\title{
QUE LUGAR É ESTE, O DA PERGUNTA PARA A FILOSOFIA? UMA LINHA DE RESPOSTA FENOMENOLÓGICO-HERMENÊUTICA
}

\author{
WHAT IS THIS PLACE, THE QUESTION FOR PHILOSOPHY? \\ A PHENOMENOLOGICAL-HERMENEUTIC RESPONSE LINE
}

Gabriel Henrique Dietrich

Aquele que quer pensar tem de perguntar. Quando alguém diz "aqui caberia uma pergunta" isto já é uma verdadeira pergunta, disfarçada pela prudência ou pela cortesia.

Gadamer, Verdade e Método

\section{RESUMO}

O objetivo central deste trabalho é explorar criticamente o tema proposto para o Encontro Regional da Residência Pedagógica em Filosofia, realizado na UFSM, a saber, "que lugar é este, o da filosofia?". Mais especificamente, esta exploração crítica toma como impulso inicial uma inflexão na formulação deste questionamento que desloca a pergunta (e o perguntar) para a posição de destaque e como o lugar da filosofia. Desde um ponto de vista histórico, a perspectiva aqui adotada aproxima-se da famosa perspectiva de Kant segundo a qual não se ensina filosofia, mas sim a filosofar. Esta aproximação permite qualificar o mote de Kant ao incluir em seu interior a pergunta enquanto tal, o que pode ser apresentado em termos condicionais do seguinte modo: se não se ensina filosofia, mas filosofar, e se a pergunta enquanto tal é central para filosofar, então a pergunta é central para ensinar a filosofar. Adicionalmente, esta qualificação é metodologicamente relevante, pois permite trazer à tona um conjunto de reflexões sobre o papel que o texto possui em sala de aula, de que modo pode ser utilizado, visando quais fins e etc. Nossa hipótese interpretativa, inspirada na fenomenologia-hermenêutica de Heidegger de Ser e Tempo, e, sobretudo, na hermenêutica filosófica de Gadamer de Verdade e Método, é a de que os verbos "refletir", "pensar", "filosofar" e "perguntar" estão intima e organicamente articulados, e que conceder papel de destaque para o ato de perguntar e para a pergunta enquanto tal abre importantes linhas de reflexão sobre o processo de ensino-aprendizagem em filosofia.

Palavras-chave: Lugar da Filosofia, Filosofar, Pergunta, Heidegger, Gadamer.

\section{Abstract}

The main objective of this work is to critically explore the theme proposed for the Regional Meeting of Pedagogical Residency in Philosophy, held at UFSM, namely, "what this is place, that of philosophy?". More specifically, this critical exploration takes as an initial impulse an inflection in the formulation of this questioning that shifts the question itself to the prominent position and as the place of philosophy. From a historical point of view, the perspective adopted here comes close to the famous Kant's perspective according to which philosophy is not 1 Doutorando do Programa de Pós-Graduação em Filosofia da UFSM. E-mail: dietrichgabriel@gmail.com. O presente trabalho foi realizado com apoio da Coordenação de Aperfeiçoamento de Pessoal de Nível Superior-Brasil (CAPES) - Código de Financiamento 001. 
taught, but to philosophize. This approach allows to qualify Kant's motto by including the question as such within it, which can be presented in conditional terms as follows: if philosophy is not taught, but philosophizing, and if the question as such is central to philosophizing, so the question is central to teaching how to philosophize. Additionally, this qualification is methodologically relevant, as it allows us to bring up a set of reflections on the role that the text has in the classroom, how it can be used, aiming at what purposes, and so on. Our interpretive hypothesis, inspired by Heidegger's phenomenology-hermeneutics of Being and Time, and, above all, by Gadamer's philosophical hermeneutics of Truth and Method, is that the verbs "to reflect", "to think", "to philosophize" and "to questioning "are intimately and organically articulated, and that grant a prominent role for the act of asking and for the question as such opens important lines of reflection on the teaching-learning process in philosophy.

Keywords: Philosophy's place; Philosophy; Question; Heidegger; Gadamer.

\section{DO LUGAR DA FILOSOFIA PARA O LUGAR DA PERGUNTA PARA A FILOSOFIA: PEQUENA INFLEXÃO INTERROGATIVA}

Não deixa de ser significativo que dentre todos os questionamentos postos pela filosofia o que talvez seja o mais inquietante e desconcertante é o questionamento por sua própria natureza. De fato, ao colocar para si a questão da natureza da filosofia, imediatamente alguém se vê às voltas com toda sorte de dificuldades que chegam mesmo a conduzir a algo assim como uma perturbação e um embaraço. Dentre outras mais, é razoável pensar que esta perturbação embaraçosa e desconcertante deriva da dificuldade de auto-justificação aberta pela adoção de uma perspectiva meta-filosófica. Dito de outro modo: com a adoção de uma perspectiva que visa tematicamente a própria filosofia e sua natureza, abre-se um enorme e complexo campo de dificuldades, dentre as quais se destaca a dificuldade de auto-justificação da própria filosofia. Mas quais indicações podem ser extraídas desde aí? O que é aberto e revelado por meio deste movimento de segunda ordem? E, mais especificamente, o que há aqui nestas indicações de relevante para uma reflexão sobre o ensino de filosofia?

Ao menos provisoriamente e em uma primeira aproximação, é possível identificar uma importante correlação entre a adoção da perspectiva de segunda ordem que tematiza a própria filosofia e as correspondentes linhas de respostas abertas por este movimento. ${ }^{2}$ Com efeito, a questão meta-filosófica da natureza da filosofia pode ser posta e formulada nos termos da pergunta por sua definição, caracterização, utilidade ou metodologia, e a cada uma destas formulações abrem-se correspondentemente diversas e variadas linhas de respostas. Naturalmente, estas diversas e complexas linhas de respostas articulam-se de muitas maneiras, podendo se complementar ou se excluir. Por exemplo, a filosofia poderia ser caracterizada provisoriamente como uma atividade reflexiva de segunda ordem que visa elucidar conceitos básicos da experiência e da ação humana. Contudo, é possível assumir compromissos metodológicos muito diferentes e com importantes implicações: a tradição denominada analítica, representada,

2 Formalmente, esta correlação talvez não gere tanto interesse e aparente mesmo trivialidade, uma vez que é de se esperar que a cada pergunta (ao menos se for bem formulada), qualquer que seja ela, esteja aberta ao menos uma linha de resposta. Contudo, considerada não-formalmente e especificamente neste contexto, esta correlação abre uma série de indicações e implica uma série de consequências para reflexões sobre o ensino de filosofia. Em grande medida, o esforço deste texto consiste justamente em explorar criticamente este horizonte interrogativo, suas consequências e também limitações. 
por exemplo, por Frege e Wittgenstein, reconhece o seu locus reflexivo predominantemente na linguagem, mais especificamente na análise de sua estrutura lógica e em seus contextos de uso, enquanto que a tradição fenomenológica, ao menos como inaugurada por Husserl, reconhece na análise da consciência, mais especificamente em seus atos e correlatos intencionais, este lugar privilegiado. ${ }^{3}$

Desse modo, a partir da adoção de uma perspectiva meta-filosófica também é possível identificar a pluralidade que está associada à própria atividade da filosofia, pois há diversos modos de se fazê-la, exercitá-la ou praticá-la. Esta pluralidade é um componente importante, pois do seu reconhecimento resulta a indicação de que na filosofia se admitem múltiplas linhas de respostas simultâneas, metodologicamente diversificadas, que estão em pé de igualdade e possuem o que poderíamos chamar de simetria epistêmica. Considerado a partir deste pano de fundo, o questionamento "que lugar é este, o da filosofia?", que sintetizou o tema do Encontro Regional da Residência Pedagógica realizado na UFSM em novembro de 2019, pode ser visto desde uma perspectiva meta-filosófica na qual são incluídos os elementos até aqui apresentados. Ou seja, ao questionamento "que lugar é este, o da filosofia?" se seguem potencialmente diversas linhas de resposta metodologicamente não-homogêneas e epistemicamente simétricas, abertas a partir de e correlatas a um movimento interrogativo de segunda ordem.

Neste texto, o compromisso metodológico adotado é com a fenomenologia-hermenêutica, sobretudo em suas variações em Heidegger e Gadamer, e seu movimento inicial consiste em uma pequena inflexão interrogativa que coloca o ato mesmo de perguntar e a pergunta enquanto tal como o lugar propriamente dito da filosofia. Concretamente, este movimento consiste em reformular o questionamento-guia do evento de tal modo a trazer a pergunta e o ato de perguntar para o primeiro plano, destacando-os como o lugar propriamente dito em que se enraíza a filosofia. Interrogativamente, esta inflexão resulta assim: que lugar é este, o da pergunta para a filosofia? Tomando esta pequena inflexão interrogativa como impulso inicial e orientação geral do trabalho, o que se buscará a seguir é pensar ressonâncias deste questionamento, e de suas correspondentes linhas de resposta, para reflexões sobre o processo de ensino-aprendizagem em filosofia.

Desde um ponto de vista histórico, a proposta aqui apresentada aproxima-se da célebre perspectiva de Kant de que não se ensina filosofia, mas sim a filosofar. ${ }^{4}$ Mais especificamente, esta aproximação permite qualificar o mote de Kant inserindo em seu interior o ato de perguntar e a pergunta enquanto tal. Condicionalmente, esta inserção qualificativa pode ser apresentada do seguinte modo: se não se ensina filosofia, mas sim a filosofar, e se o ato de perguntar e a pergunta enquanto tal são centrais para filosofar,

3 Naturalmente, há importantes consequências em se adotar qualquer destas linhas metodológicas, por exemplo, quanto àquilo que se considera como sendo propriamente o escopo de atuação da própria filosofia, que pode ser mais ou menos amplo. Sobre uma bastante adequada apresentação das diferenças metodológicas e das consequências que delas seguem, Tugendaht tem trabalhos excelentes (conferir, por exemplo, o seu Lições Introdutórias à Filosofia Analítica da Linguagem e, mais especificamente, a seu artigo Reflexões sobre o método da filosofia do ponto de vista analítico (1992)).

4 Não é incomum referir esta perspectiva de Kant para a Crítica da Razão Pura, mais especificamente para a doutrina transcendental do método (p. 660, 1989). Apesar de ela poder ser lida ali, sua formulação mais expressa e direta encontra-se no curso de Kant conhecido como Lectures on Logic (1998, p. 38). É relevante observar isto na medida em que permite colocar a pergunta pela relação entre os dois textos, mais especificamente a pergunta por como a diferença entre filosofar e filosofia é operativa em cada um deles, uma vez que a Crítica não era exatamente um curso e material para aulas, enquanto que a Lógica sim. Esta é uma tarefa que é apenas mencionada aqui e que deixo em aberto para desdobramentos futuros. 
então a pergunta enquanto tal e o ato de perguntar são centrais para se ensinar a filosofar. Como um passo anterior a este movimento condicional que visa explorar consequências do reconhecimento da centralidade da pergunta e do ato de perguntar para o processo de ensino-aprendizagem de filosofia, será apresentado o horizonte teórico no qual ele consta não apenas condicionalmente, mas categórica, orgânica e vitalmente, a fenomenologia hermenêutica de Heidegger e a hermenêutica filosófica de Gadamer. ${ }^{5}$

\section{A PERGUNTA COMO O LUGAR DA FILSOFIA: ENTRE HEIDEGGER E GADAMER, E UM POUCO MAIS ADIANTE}

É bastante conhecido que o pensamento de Heidegger sempre esteve às voltas com o conceito de ser. De fato, não seria exagero considera-lo como um filósofo de um só pensamento, apesar das significativas modificações internas que permitem reconhecer diferenças importantes entre o jovem Heidegger e o Heidegger tardio. No período de sua obra conhecido como "década fenomenológica", que inclui Ser e Tempo, este pensamento é formulado em termos da pergunta pelo sentido do ser. Embora seja comum na literatura especializada destacar inicialmente o componente hermenêutico desta pergunta, isto é, que o que se visa é elucidar o sentido do ser (por exemplo, REIS, p. 137-155, 2000), aqui o destaque é deslocado para a pergunta enquanto tal. É notável que o programa inteiro da ontologia fundamental esteja antecedido e orientado por uma pergunta. Em verdade, as páginas iniciais de Ser e Tempo são atravessadas de ponta a ponta por uma série de perguntas que demarcam o tom e a atmosfera interrogativa no interior da qual o pensamento de Heidegger se movimenta. ${ }^{6}$

Deixando de lado os objetivos específicos e os desdobramentos efetivos do programa da ontologia fundamental, cabe aqui apenas destacar que a orientação assumida por Heidegger lhe dá acesso a uma perspectiva muito particular da história da filosofia. Grosso modo, a história da filosofia pode ser parcialmente lida como a história de um longo esquecimento, a saber, do esquecimento do ser. Considerada desde esta perspectiva, a filosofia de Heidegger apresenta-se como um contra-movimento ao esquecimento, isto é, como um esforço e tentativa de recolocar novamente e expressamente o ser enquanto questão. ${ }^{7}$ Assim, não é irrazoável pensar que ao esquecimento que acompanha a história da filosofia

5 No mínimo seria temerário pensar que se trata de um único horizonte o que fornece esta linha de pensamento. Por exemplo, para a dialética socrático-platônica as perguntas cumprem uma função decisiva, chegando mesmo, em situações aporéticas, a consistir no limite da reflexão. Nesse sentido, o que se ensaia aqui é uma tentativa de se pensar estas questões, e que, naturalmente, pode ser articulada com outras mais, como a maiêutica.

6 Não seria exagero afirmar que o contorno geral das linhas mestras que delineiam o pensamento de Heidegger em Ser $e$ Tempo é apanhado perfeitamente bem com o contorno das linhas do ponto de interrogação, pois a primeira e a última frase de Heidegger nesta obra são ambas perguntas. Assim, não apenas o texto começa e termina com uma pergunta, mas entre uma e outra a atmosfera que oxigena o pensamento de Heidegger é notavelmente preenchida por perguntas.

7 Longe de ser um mero movimento teórico e adequadamente capturado com uma descrição em terceira pessoa, a recolocação da questão do ser é profundamente auto-implicada por aquele que a recoloca. Esta auto-remissão do questionar o sentido do ser em geral para o questionar o sentido do próprio ser permite destacar o traço existencial (e transcendental) que acompanha o pensamento de Heidegger. Como o objetivo aqui é apenas caracterizar muito genérica e brevemente a centralidade da pergunta e do ato de perguntar, não será possível explorar a dimensão existencial deste deslocamento. Esta é uma importante tarefa que permanece em aberto para desdobramentos ulteriores: a de pensar existencialmente o processo de ensino-aprendizagem. 
corresponde, em alguma medida, a ausência da colocação de determinadas perguntas ou questões. ${ }^{8}$ Desta caracterização, segue-se uma importante implicação metodológica, pois os textos legados pela tradição são recebidos, lidos e interpretados à luz de perguntas que estabelecem o seu horizonte de sentido, a sua inteligibilidade. Aos olhos de Heidegger, tais perguntas são notavelmente de corte ontológico, o que significa que a recepção de obras não é passiva e meramente reconstrutiva, mas que, ao contrário, é altamente criativa e propositiva. ${ }^{9}$

Esta recepção hermenêutica criativa e propositiva para a qual perguntas figuram centrais é desdobrada por Gadamer e inserida não apenas no contexto dos textos da tradição, mas vinculada à própria experiência enquanto tal. Não cabe aqui entrar especificamente no tema do caráter hermenêutico da experiência ou do tipo determinado de experiência que se poderia qualificar como hermenêutica, pois para isso seria preciso introduzir toda uma bateria bastante complexa de conceitos que acabaria por ultrapassar o escopo do presente trabalho. ${ }^{10}$ Para permanecer neste marco restrito, basta destacar que Gadamer acolhe (ainda que eventualmente criticamente) a orientação geral de Heidegger, e a formula expressamente em diversas passagens de Verdade e Método. Mais especificamente, alguns destes traços são especialmente notáveis no subcapítulo intitulado "A primazia hermenêutica da pergunta", que está inserido no capítulo maior "Os traços fundamentais de uma teoria da experiência hermenêutica", para o qual voltamos nossa atenção agora.

Como bastante bem indicado pelos títulos, neste contexto os esforços de Gadamer estão concentrados na elaboração de um conceito ou teoria da experiência hermenêutica, e para este fim é conferida

8 Neste ponto é preciso fazer uma ressalva terminológica, pois aparentemente há um vacilo, hesitação ou vagueza que permite passar indiscriminadamente de "perguntas" para "questões". Esta é uma dificuldade que decorre em parte do modo como Heidegger articula a questão do ser, que também é apresentada em termos do problema ontológico. Deixando de lado especificidades e detalhes que eventualmente podem ser importantes, a distinção relevante aqui é sobretudo entre perguntas e problemas, pois Gadamer a faz expressamente (p. 553,1999). Como esta distinção será brevemente retomada a seguir, cabe aqui apenas uma elucidação muito singela: a diferença entre perguntas, questões e problemas pode ser pensada em termos de uma diferença de grau de generalidade e abstração (problemas são muito mais gerais do que perguntas). 9 Naturalmente, este tipo de orientação recebe muitas objeções e pode mesmo ser considerado como hermeneuticamente suspeito, uma vez que as interpretações podem estar a serviço de teses alheias a e extrapolarem os limites do texto. De fato, considerando, por exemplo, as interpretações da Crítica da Razão Pura, Heidegger afasta-se das escolas neo-kantianas dominantes de seu tempo, e a custo de muita polêmica. Em seu favor, contudo, poderíamos procurar sopesar dois movimentos internamente articulados: o de reconstrução exegética escolar, por um lado, e, por outro, o de apropriação interpretativa. Não é necessário pensar os dois movimentos como mutuamente excludentes, e pode haver ganho interpretativo em se ler criticamente um texto à luz de cada um deles, considerando tanto a letra quanto o espírito do texto. De fato, ao menos em parte, este é o movimento hermenêutico adotado por Heidegger em cursos como Lógica, a pergunta pela verdade, ou em Kant e o problema da metafísica, pois nestes cursos são apresentadas interpretações pouco escolares e ortodoxas da Crítica da Razão Pura, mas que ao mesmo tempo são cotejadas e parcialmente comparadas de modo crítico com outras interpretações, sobretudo a das escolas neo-kantianas da época.

10 Apenas para mencionar alguns, esta bateria é composta pelos conceitos de consciência histórica, história efeitual, negatividade e finitude. Centralmente consta aqui um conceito especial de experiência, que é contrastado com outros, oriundos de Aristóteles e Bacon, cuja orientação e delimitação não são extraídas das ciências. Considerando algumas notas características deste conceito hermenêutico de experiência, talvez não seja irrelevante considera-lo à luz da experiência em contextos de ensino-aprendizagem. 
à pergunta uma posição de primazia (p. 533-555, 1999). Mas em que consiste exatamente esta primazia? Considerando que primazia indica relação de anterioridade, qual é o outro relatum? E quais as consequências do seu reconhecimento para reflexões que visem o ensino de filosofia? Mesmo sem ter a pretensão de oferecer linhas de respostas completas, exaustivas e sistemáticas para estas questões, de saída é possível reconhecer que ambas estão internamente ligadas. Esta interligação pode ser desdobrada tomando como fio condutor a rede dos conceitos de abertura, sentido, horizonte, interpretação, compreensão e, claro, o de pergunta, com o qual apropriadamente começarei, dada a sua já referida primazia.

Bem ao estilo hermeneuta, o movimento inicial de Gadamer é apresentar e caracterizar a pergunta à luz de uma imagem, à luz da imagem de abertura. Em linhas gerais, perguntar é apresentado como colocar algo no aberto ou em abertura (GADAMER, 1999, p. 535). Mais especificamente, este colocar em aberto é também direcionar ou colocar algo em determinada orientação. O conceito que captura tanto esta abertura quanto este direcionamento é o clássico conceito hermenêutico de sentido. Desse modo, o movimento inicial de Gadamer consiste em vincular pergunta e sentido. Mais abstratamente, este vínculo é apresentado em termos de questionabilidade: diante de perguntas algo é posto em aberto e acessado a partir de determinada direção, isto é, o interrogado é posto em perspectiva. Como a própria imagem de abertura sugere, isto é feito dentro de um horizonte que delimita e estabelece restrições: a pergunta é sempre feita a partir de uma determinada situação hermenêutica parcialmente restritiva e promotora, finita e animadora.

Apesar de não estar restrita a textos e englobar também outros índices e expressões do espírito e da história, esta perspectiva de Gadamer é particularmente importante na recepção da própria tradição filosófica. Sinteticamente, esta perspectiva pode ser lida na seguinte formulação:

O fato de que um texto transmitido se converta em objeto da interpretação quer dizer, para começar, que coloca uma pergunta ao intérprete. A interpretação contém, nesse sentido, sempre uma referência essencial constante à pergunta que foi colocada. Compreender um texto quer dizer compreender essa pergunta. Mas isso ocorre, como já mostramos, quando se ganha o horizonte hermenêutico. Nós reconhecemo-lo agora como o horizonte do perguntar, no qual se determina a orientação de sentido do texto. (GADAMER, 1997, p. 544, grifo do autor)

Esta importante passagem permite que seja visualizado um vínculo adicional, a saber, entre interpretação e pergunta, por um lado, e entre compreensão e pergunta, por outro. Entre as ações de compreender e interpretar figuram centralmente a pergunta e o horizonte do perguntar, e isso é bastante relevante para se pensar o ensino de filosofia de modo geral e, mais especificamente, algumas questões metodológicas. Por exemplo, desde esta perspectiva aberta por Heidegger e desdobrada por Gadamer, quaisquer que sejam os textos da tradição que consideremos, sempre estarão referidos a um conjunto de perguntas a partir do qual obtém a sua própria inteligibilidade, o horizonte de sentido no interior do qual estão dispostos seus conceitos e relações conceituais." Assumindo isso para a

11 É bastante bem conhecida uma linha de recepção da história da filosofia em termos de uma história de problemas. Esta linha de recepção possui importantes ressonâncias para reflexões sobre o processo de ensino-aprendizagem em filosofia, pois os problemas seriam algo assim como satélites ao redor dos quais os diferentes textos e autores orbitariam. Uma excelente contribuição nesta direção pode ser lida em A Filosofia a partir de seus problemas, de Mário Porta. Contudo, Gadamer 
perspectiva do leitor, cuja aspiração é a de percorrer as sendas de sentido e inteligibilidade do texto, estar de posse de tais perguntas é um momento essencial para a sua compreensão. Isso significa que a relação de leitura e estudo com o texto é uma relação dialógica e conversacional, pois se por um lado o texto traz consigo uma série de perguntas que configuram seu horizonte de sentido, por outro, dada a situação hermenêutica de sua recepção, este horizonte é interpretativamente acolhido e apropriado. A expressão gadameriana que designa e captura esta complexa articulação entre os horizontes do texto e da situação hermenêutica é "fusão de horizontes". ${ }^{12}$

A fusão de horizontes resultante da aproximação da recepção e da produção de texto toma a pergunta e o ato de perguntar como um de seus elementos essenciais, pois as perguntas que cada um traz consigo são o que possibilita esta mútua conjugação. Considerado em relação a contextos de ensino-aprendizagem em filosofia, este processo fornece algumas indicações metodológicas importantes, pois o trabalho em sala de aula terá sempre junto consigo o esforço de apresentar, discutir, explicitar e formular as perguntas às quais o texto está referido e que lançam luz e senso de direção aos conceitos ali presentes. Adicionalmente, na medida em que simplesmente não há acesso ao texto sem que seja a partir de uma situação hermenêutica, esta perspectiva levanta uma preocupação importante, a saber, a de considerar de que modo perguntas trazidas pela situação hermenêutica do intérprete podem ser relidas à luz de perguntas que conferem o horizonte do texto. Naturalmente, dado o caráter hermenêutico desta orientação, esta preocupação não é unilateral, mas circular, pois também se considera de que modo as perguntas que conferem o horizonte do texto podem ser lidas à luz das perguntas trazidas pela situação hermenêutica do intérprete.

Apenas a título de exemplo, poderíamos considerar qualquer texto de filosofia à luz destas considerações e nos perguntarmos o seguinte: quais são as perguntas que este texto traz consigo? Quais são as que estão expressa e explicitamente postas? Quais estão subentendidas? Quais perguntas não estão postas? Por quê? Naturalmente, não se trata de tentar esgotar o sentido e responder exaustivamente as perguntas de um determinado texto, se é que isso é possível, mas apenas procurar maneiras de trazer a sua força interrogativa para junto de nós e dos demais. Esta atitude, notadamente próxima de uma orientação fenomenológico-existencial, pensa que textos não são um mero amontoado de palavras e

faz uma distinção formal entre perguntas e problemas (1999, p. 553), pois problemas seriam abstrações bastante distantes da experiência na qual as perguntas se enraízam. Com efeito, seria um trabalho relevante discutir consequências desta distinção para as propostas de ensino-aprendizagem em filosofia cujo centro de gravidade são os problemas. Dentro dos limites deste trabalho, a distinção é apenas mencionada e não explorada mais detalhadamente, e como hipótese de trabalho para desdobramentos ulteriores pensamos que o conceito de problema é mais adequado para caracterizar áreas e campos da própria filosofia (como problemas epistêmicos, estéticos ou ontológicos) que em última instância se fenomenalizam por meio das perguntas nas quais eles são elaborados e a partir das quais recebem linhas de resposta.

12 Certamente este é um dos conceitos centrais do pensamento de Gadamer, o que justificaria uma análise muito mais sistemática e rigorosa. Deixando de lado muitas de suas notas características, por exemplo, em que medida este é um conceito debitário do conceito fenomenológico de horizonte, uma delas merece um breve destaque, dado o contexto. Na ideia mesma de fusão consta algo assim como compreensão e também ressoa a ideia de "comum acordo". Se esta for uma nota característica do conceito de fusão de horizontes, então ela precisa ser avaliada criticamente, especialmente quando aproximada de reflexões sobre o processo de ensino-aprendizagem. É altamente discutível que, por exemplo, o resultado deste processo seja a fusão de horizontes no sentido de seus partícipes entrarem em comum acordo sobre algo. 
símbolos, mas são expressões da vida de autores, autoras e tradições que se fundem horizontalmente com expressões da vida do intérprete. ${ }^{13}$

Desde a perspectiva de Gadamer, o esforço em assumir esta postura conduz ao pensamento propriamente dito, pois colocar-se na questionabilidade do texto é colocar-se para si mesmo as questões que vicejam ali, e ao mesmo tempo pensa-las a partir de sua própria situação hermenêutica. Em última instância, portanto, os verbos pensar, ler, interpretar e perguntar formam um todo articulado e orgânico, todo este que constitui, ao menos parcialmente, o todo da própria filosofia e do filosofar.

\section{CONSIDERAÇÕES FINAIS}

Ao questionamento "que lugar é este, o da filosofia?" é possível oferecer muitas e variadas linhas de respostas. Considerado desde uma perspectiva fenomenológico-hermenêutica, este é um questionamento que nos aproxima de nós mesmos, por assim dizer, pois a filosofia não é entendida como um artifício ou algo estranho, exótico e externo. Desse modo, a pergunta pelo lugar da filosofia curiosamente passa a ser também uma pergunta sobre nós mesmos, uma vez que no núcleo mesmo da identidade humana figura centralmente a questão e o perguntar constantes e incontornáveis pelo seu próprio ser. Assumindo esta orientação geral e tomando Ser e Tempo e Verdade e Método como pano de fundo, aquilo que se abre como o lugar propriamente dito da filosofia é justamente esta dimensão interrogativa, o ato de perguntar e a pergunta enquanto tal. Mas seria este o único lugar da filosofia? Não haveria aqui outras vias de resposta igualmente aceitáveis?

Embora não tenham sido o foco direto e detido de atenção da perspectiva aqui adotada, os argumentos e a argumentação também figuram centralmente para a filosofia, e a ausência de um reconhecimento expresso e nítido não justifica concluir que nosso trabalho os desconsidera por completo. Ao contrário, a perspectiva assumida aqui é a de que argumentos não só são centrais como são mesmo decisivos, pois oferecem algo assim como a estrutura no interior da qual são desdobradas diversas perguntas. Imageticamente, isto poderia ser dito destacando que se por um lado as perguntas fornecem algo assim como o horizonte e a constelação de inteligibilidade a partir da qual é possível se orientar junto a um texto, por outro lado este horizonte só é possível por sobre alguma base que o sustenta e mantém, e argumentos são fortes candidatos a assumir ao menos parte desta posição basilar e de sustentação. Ou seja, o horizonte do perguntar de um texto que é sempre aberto a partir de uma determinada situação hermenêutica encontra seus limites na esfera do argumentável, que, por sua vez, é sempre posta na perspectiva da questionabilidade de algo. Considerando especialmente o contexto de ensino-aprendizagem de filosofia, 13 Conforme apresentadas até aqui, estas pequenas considerações podem ser consideradas excessivamente genéricas ou até mesmo formais, uma vez que dizem respeito a uma atitude geral diante de quaisquer textos. No contexto da apresentação no evento, estas considerações foram desformalizadas e As Meditações Metafísicas de Descartes e a epistemologia de modo geral serviram de exemplo para ilustrar um pouco mais concretamente a proposta que aqui se ensaia. Contudo, dada a mudança de registro e de mídia, fazer o mesmo neste contexto implicaria em especificar, citar e analisar determinadas passagens textuais, seja individualmente de Descartes, seja mais genericamente de uma área como a epistemologia, o que conduziria o texto para uma direção muito menos introdutória e muito mais propositiva. Neste contexto, o que se pretende é apenas abrir sugestivamente alguns caminhos a se pensar tanto o lugar da filosofia enquanto pergunta quanto consequências da adoção deste lugar para o processo de ensino-aprendizagem em filosofia. 
a articulação inclusiva e mutuamente restritiva de argumentos e perguntas é de longe preferível à exclusão de um destes momentos, que isoladamente tende a fornecer apenas parcialmente algo daquilo que é requerido para que cada um faça de si mesmo isto, o lugar da filosofia.

\section{REFERÊNCIAS}

DESCARTES, R. Meditações Metafísicas. Coleção Os Pensadores. ed. Abril. 1973

GADAMER, H-G. Verdade e Método. Ed. Vozes. 1999.

HEIDEGGER, M. Ser y Tiempo. Ed. Trotta. 2009.

HEIDEGGER, M. Logic, The Question of Truth. Indiana Universisty Press. 2010.

KANT, I. Crítica da Razão Pura. Ed Calouste Goulbenkian. 1989.

KANT, I. Lectures on Logic. Cambridge Companion of the Works of Immanuel Kant. Cambdridge. 1992. PORTA, M. A filosofia a partir de seus problemas. Ed Loyola.

REIS, R. R. A ontologia Hermenêutica de 'Ser e Tempo', in Filosofia Hermenêutica. Ed UFSM, 2000.

TUGENDHAT. Reflexões sobre o método da filosofia a partir do ponto de vista analítico. Revista Problemata. UFPB. 1992. 
